\title{
PRODUÇÃO DE GRÃOS E FORRAGEM EM FUNÇÃO DA DISPONIBILIDADE LUMINOSA EM SISTEMA DE INTEGRAÇÃO LAVOURA-PECUÁRIA-FLORESTA
}

\author{
EDUARDO DE PAULA SIMÃO ${ }^{1}$, MIGUEL MARQUES GONTIJO NETO², \\ SILVIO NOLASCO DE OLIVEIRA NETO3 ${ }^{3}$, JOÃO CARLOS CARDOSO GALVÃO, \\ EMERSON BORGHI², DENIZE CARVALHO MARTINS ${ }^{1}$ e ÁLVARO VILELA DE RESENDE²
}

IDoutorandoem Fitotecnia pela Universidade Federal de Viçosa.
e-mail: eduardosimao.agro@yahoo.com.br; denizecarvalhom@yahoo.com.br.
${ }^{2}$ Pesquisadorda Embrapa Milho e Sorgo.e-mail: miguel.gontijo@embrapa.br;
emerson.borghi@embrapa.br; alvaro.resende@embrapa.br
${ }^{3}$ ProfessordaUniversidade FederaldeViçosa.e-mail: snolasco@ufv.br; jgalvão@ufv.br.

Revista Brasileira de Milho e Sorgo, v.17, n.1, p. 111-121, 2018

\begin{abstract}
RESUMO - Neste trabalho, objetivou-se avaliar a produtividade da forragem e grãos de milho e do capim braquiária em consórcio, submetidos a diferentes níveis de sombreamentos proporcionados pelos renques de eucaliptos, em sistema de Integração Lavoura-Pecuária-Floresta, na região de Sete Lagoas-MG. O experimento foi conduzido na área experimental da Embrapa Milho e Sorgo, em Sete Lagoas-MG, em área de cultivo de eucalipto (Eucalyptus urophylla, clone AEC 1528) implantado em 29 de outubro de 2013, em espaçamento $15 \times 2 \mathrm{~m}$ entre plantas. Em 24 de novembro de 2015, foi realizada a semeadura simultânea em sistema plantio direto do milho (AG 8088 VT PRO) consorciado com capim braquiária (Urochloa brizantha $\mathrm{cv}$. Marandu) em espaçamentos de $0,70 \mathrm{~m}$ entre linhas, a uma distância de 1 metro entre a primeira linha de semeadura do milho/braquiária e os renques de eucalipto. As produtividades de grãos e forragem de milho e de milho mais capim entre os renques de eucalipto foram semelhantes às produtividades em pleno sol a partir de 3,8 m de distância entre as linhas de milho e os renques de eucalipto. A produtividade de grãos e de forragens foi diretamente influenciada pela redução da distância entre as linhas de semeadura e os renques de eucalipto com três anos de implantação em espaçamento de $15 \times 2$. O componente arbóreo no sistema de Integração Lavoura-PecuáriaFloresta altera o ambiente no sub-bosque, reduzindo a incidência de radiação fotossinteticamente ativa entre os renques, diminuindo diretamente as produtividades de forragem e grãos de milho em cultivo consorciado com U. brizantha. Palavras-chave: Zea mays, U. brizantha, eucalipto, cultivo consorciado.
\end{abstract}

\section{GRAIN AND FORAGE PRODUCTION IN THE FUNCTION OF LUMINOUS AVAILABILITY IN INTEGRATED CROP-LIVESTOCK-FORESTRY SYSTEMS}

\begin{abstract}
The objective of this work was to evaluate the productivity of grass and maize forage, and maize grains submitted to different levels of shade provided by the eucalypt trees, in Integrated Crop-Livestock-Forest system, in the region of Sete Lagoas, State of Minas Gerais, Brazil. The experiment was carried out in the experimental area of Embrapa Milho e Sorgo, in Sete Lagoas, MG, in an area of eucalypt (Eucalyptus urophylla, clone AEC 1528) implanted on October 29, 2013, spaced $15 \times 2$ m between plants. On November 24, 2015, no-tillage system (AG 8088 VT PRO) was intercropped with Brachiaria grass (Urochloa brizantha cv. Marandu) at $0.70 \mathrm{~m}$ between rows, at a distance of 1 meter between the first sowing line of maize/Brachiaria and eucalypt rows. The yields of maize forage, maize grains and Brachiaria among the eucalypt rows were similar to the productivities in full sun from $3.8 \mathrm{~m}$ distance between maize and eucalypt lines. Grain yield and maize fodder yields were directly influenced by the reduction of the distance between the sowing lines and the eucalypt rows with three years of implantation at $15 \times 2 \mathrm{spacing}$. The arboreal component in Integrated Crop-Livestock-Forest system alters the environment in the sub-forest, reducing the incidence of photosynthetically active radiation among the ranks, directly reducing forage and maize grains yields in intercropping system with $U$. brizantha.
\end{abstract}

Keywords: Zea mays, U. brizantha, eucalypt, intercropping system. 
A Integração Lavoura-Pecuária-Floresta (ILPF) é um sistema de produção sustentável que busca melhorar as condições de áreas degradadas incluindo diferentes espécies, de forma sinérgica, afim de recuperar e manter a produtividade (Balbino et al., 2011), tornando-se uma alternativa para regiões onde predomina o uso de pastagem como forma de produção de carne e leite e que estão sofrendo com a degradação das pastagens, como a região do Cerrado brasileiro. Segundo Andrade et al. (2015), o Cerrado brasileiro possui cerca de 53 milhões de hectares de pastagens cultivadas em processo de degradação, reduzindo a viabilidade econômica e resultando em baixo aproveitamento do território da região, que é considerada atualmente a principal produtora de carne do Brasil.

O consórcio entre diferentes espécies vegetais tem sido um desafio, já que a produtividade das lavouras pode ser reduzida, se comparado a sistemas em monocultivo, em função da competição exercida de acordo com os arranjos e culturas que compõem o sistema. Neste contexto, busca-se adequar a disposição dos componentes afim de reduzir a competição. De acordo com Gontijo Neto et al. (2014), o sistema ILPF envolvendo o milho e braquiária em consorcio é recomendado para regiões com aptidão agroclimática para a cultura do milho, tendo inclusive incentivos de financiamento específicos de programas do governo, como o Plano ABC (Agricultura de Baixo Carbono).

O consórcio de milho e capim com eucalipto se tornou uma das estratégias de maximizar a sustentabilidade da pecuária para a região Central de Minas Gerais, onde predomina a atividade pecuária como principal fonte de renda dos produtores. Além disso, na região existe uma elevada demanda de produção de madeira para atender indústrias que utilizam o carvão vegetal como fonte de energia. Conforme Gontijo Neto et al. (2014), o milho é uma cultura utilizada como fonte de alimento para bovinos nesta região, e apresenta boa plasticidade quando consorciado com braquiária, mas quando recebe influência das copas do eucalipto pode ter sua capacidade produtiva reduzida.

A escolha do espaçamento é determinante no planejamento do sistema, já que a produtividade das culturas pode ser afetada de acordo com o número de árvores por área. Tratando-se de plantas $\mathrm{C} 4$, como o milho e o capim, há uma alta demanda de luz, e esse nível de sombreamento atua fortemente sobre a interceptação da radiação fotossinteticamente ativa sobre o dossel das plantas, reduzindo a fixação de $\mathrm{CO}_{2}$ que se converte em carboidratos que compõe a biomassa de grãos e forragem (Zhu et al., 2010). Sendo assim, o milho e o capim entre os renques de eucaliptos são influenciados de acordo com o nível de sombreamento proporcionados pelas árvores, onde espera-se que as plantas mais próximas do renque serão mais afetadas.

Em busca de informações sobre o nível de sombreamento proporcionado pela distância do renque e sua influência sobre a produtividade de forragem e de grãos em sistema ILPF, este trabalho foi desenvolvido com o objetivo de avaliar a produtividade da forragem e de grãos de milho e do capim em consórcio, submetidos a diferentes níveis de sombreamentos proporcionados pelos renques de eucaliptos, em Sistema de Integração Lavoura-Pecuária-Floresta, em Sete Lagoas-MG.

\section{Material e Métodos}

Um experimento foi conduzido na área experimental da Embrapa Milho e Sorgo, em Sete Lagoas-MG, nas coordenadas geográficas: latitude de 19²9.106' S e longitude de $44^{\circ} 10.773^{\prime} \mathrm{W}$ e altitude de $708 \mathrm{~m}$. O solo foi classificado como Latossolo Vermelho distrófico típico (LVd). Antes da implantação 
do experimento foi realizada análise química do solo em outubro de 2012 (Tabela 1). Em 16 de outubro de 2013, foi feita a aplicação de $3 \mathrm{t} \mathrm{ha}^{-1}$ de calcário e $2 \mathrm{t}$ $\mathrm{ha}^{-1}$ de gesso agrícola. Antecedendo este experimento, nas safras de 2013/14 e 2014/15, nas faixas entre os renques de eucalipto, foi semeado o consórcio do milho/capim com a aplicação de $400 \mathrm{~kg} \mathrm{ha}^{-1}$ de NPK 08-28-16 na semeadura mais $200 \mathrm{~kg} \mathrm{ha}^{-1}$ de ureia a cada ano.

Efetuou-se a implantação dos renques de eucalipto (Eucalyptus urophylla, clone AEC 1528) de aproximadamente $80 \mathrm{~m}$ de comprimento em 29 de outubro de 2013, em sistema semimecanizado, com espaçamento $15 \times 2 \mathrm{~m}$ entre plantas. Foram utilizadas mudas clonais com adubação no sulco de $200 \mathrm{~kg} \mathrm{ha}^{-1}$ de superfosfato simples, mais 120 gramas por planta da formulação NPK 06-30-06 com 0,5\% B e 1,5\% $\mathrm{Zn}$, metade em cada lado da cova, distanciado 15 a 20 $\mathrm{cm}$ da muda na semana seguinte ao plantio e adubação de cobertura na projeção da copa utilizando 120 gramas por planta de NPK 20-00-20 aos 60 dias após o plantio. Em fevereiro de 2014, aplicaram-se 15 gramas por planta de ácido bórico na projeção da copa de cada árvore. Em setembro de 2014, as árvores foram desramadas a até $1 / 3$ da altura da árvore. Realizouse a mensuração do componente arbóreo em 21 de março de 2016, resultando em altura média de 12,4 metros e diâmetro na altura do peito (DAP) de 12,2 centímetros.
Em 24 de novembro de 2015, realizou-se a semeadura do milho (AG 8088 VT PRO) consorciado com capim-braquiária (Urochloa brizantha cv. Marandu) com espaçamento de 0,70 metros entre linhas, resguardando a distância de 1 metro entre a primeira linha de semeadura do milho/braquiária dos renques de eucalipto e em uma área contígua a pleno sol (PS). O plantio foi realizado no Sistema Plantio Direto (SPD) utilizando-se uma semeadora-adubadora com compartimentos independentes de sementes (grãos e capins), de três linhas, com as sementes de milho depositadas a $5 \mathrm{~cm}$ e a do capim entre 2 e $3 \mathrm{~cm}$ de profundidade. Os dados de precipitação pluviométrica e temperatura nos meses de condução do experimento encontram-se apresentados na Figura 1.

O tratamento de sementes de milho foi realizado com inseticidas Imidacloprido e Tiodicarbe no momento da semeadura visando a densidade de plantio de 70.000 plantas ha $^{-1}$, consorciado com o capim Urochloa brizantha cv. Marandu, tratadas com o inseticida Fipronil, com taxa de semeadura de $4 \mathrm{~kg} \mathrm{ha}^{-1}$ de sementes puras viáveis. A adubação no momento da semeadura consistiu de $400 \mathrm{~kg} \mathrm{ha}^{-1}$ da formulação NPK 08-28-16 e de cobertura, $400 \mathrm{~kg} \mathrm{ha}^{-1}$ da formulação NPK 20-0020 , realizada em 18 de dezembro de 2015. O controle de plantas invasoras sucedeu-se em 30 de novembro de 2015 com a aplicação de 31 ha $^{-1}$ de Atrazina.

Os tratamentos consistiram das distâncias das linhas de milho/capim em relação aos renques de eu-

Tabela 1 - Atributos químicos do solo da área experimental na profundidade de 0-10 e 10-20 cm, antes da instalação do experimento.

\begin{tabular}{|c|c|c|c|c|c|c|c|c|c|c|c|}
\hline \multirow{2}{*}{ Prof. } & \multirow[t]{2}{*}{$\mathrm{pH}$} & & & $\mathrm{K}$ & $\mathrm{H}+\mathrm{Al}$ & $\mathrm{Al}$ & $\mathrm{Ca}$ & $\mathrm{Mg}$ & SB & CTC & \multirow[t]{2}{*}{ V } \\
\hline & & dag $\mathrm{kg}^{-1}$ & \multicolumn{2}{|c|}{$\mathrm{mg} \mathrm{dm}^{-3}$} & & & & & & & \\
\hline $0-10 \mathrm{~cm}$ & 5,5 & 5,11 & 48,9 & 294 & 6,37 & 0 & 5,8 & 1,16 & 7,7 & 14 & 54,7 \\
\hline $10-20 \mathrm{~cm}$ & 5,6 & 4,99 & 27,1 & 173 & 8,35 & 0 & 4,4 & 0,79 & 5,6 & 13 & 40,2 \\
\hline
\end{tabular}




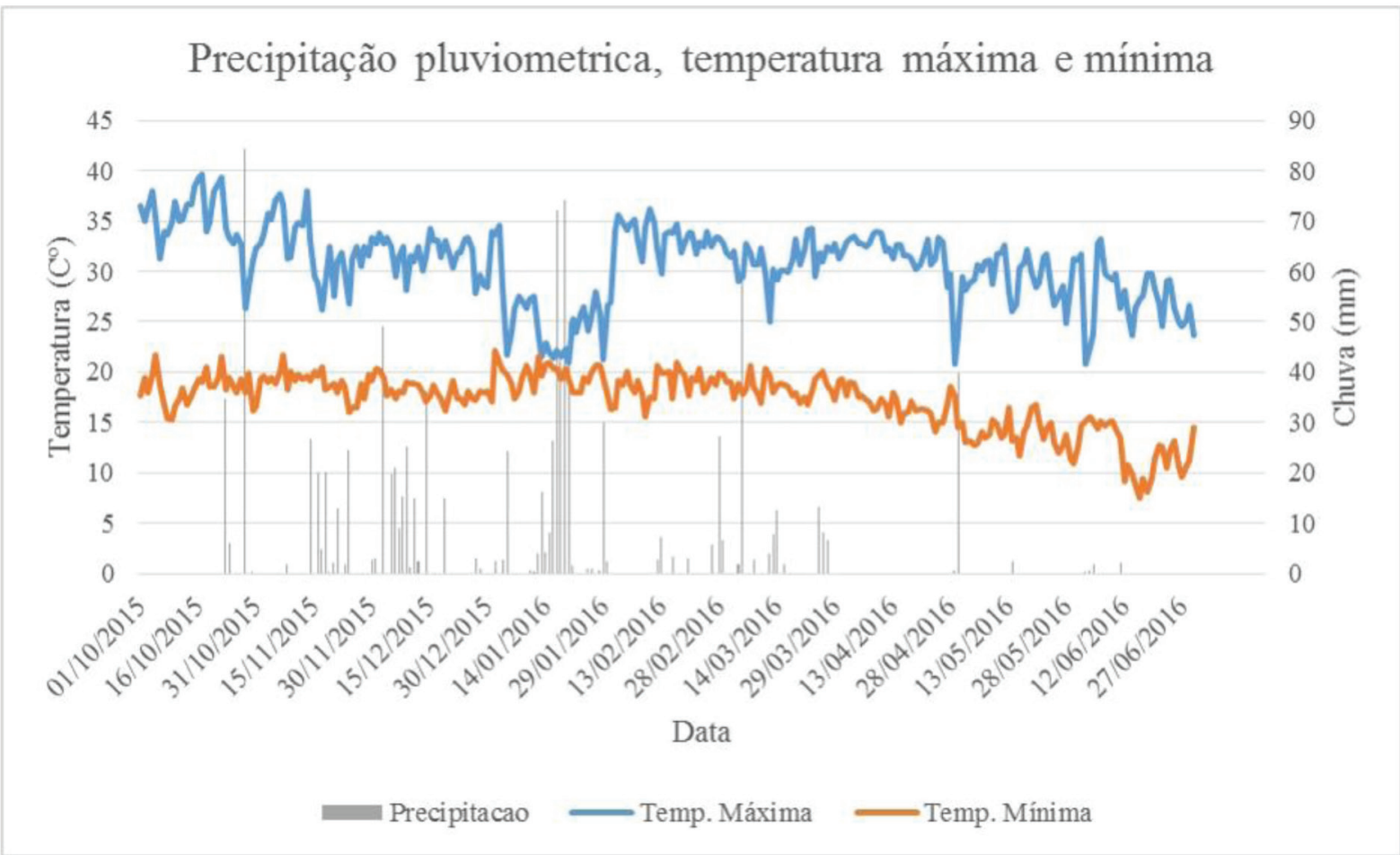

Figura 1 - Dados de precipitação pluviométrica $(\mathrm{mm})$ e temperaturas máxima e mínima durante a condução do experimento na área experimental da Embrapa Milho e Sorgo, em Sete Lagoas-MG, no período de outubro de 2015 a junho de 2016.

calipto, sendo avaliadas as linhas 1 (1 m), 3 (2,4 m), 5 $(3,8 \mathrm{~m})$ e $7(5,2 \mathrm{~m})$ mais um tratamento com o milho e capim semeado a pleno sol (PS). Realizou-se a amostragem em quatro pontos da faixa de plantio entre os renques de eucalipto e na área a pleno sol. A avaliação da radiação fotossinteticamente ativa (RFA) ocorreu após a semeadura do milho e capim, em três momentos durante o ciclo do milho, nos dias 16/12/2015, 01/02/2016 e 06/04/2016, que correspondem aos estádios de desenvolvimento da cultura do milho $\mathrm{V}_{3}-\mathrm{V}_{4}$, $\mathrm{R}_{1}$ e $\mathrm{R}_{6}$, respectivamente, segundo Fancelli e Dourado Neto (2000). As amostragens foram realizadas a distâncias de 1,0 m, 2,4 m, 3,8 m e 5,2 m dos renques de eucaliptos e a pleno sol, nos períodos da manhã (8h00), meio-dia (12h00) e tarde (16h00), utilizando-se o sensor SunScan probe v1.02R. Estimou-se a porcentagem de RFA em função dos valores da leitura em cada parcela experimental dividido pela leitura realizada no pleno sol, tendo esse valor multiplicado por 100 afim de se ter a porcentagem de RFA incidente sobre os tratamentos.

As amostragens de plantas e grãos ocorreram quando o milho atingiu o ponto para ensilagem $\left(\mathrm{R}_{3}\right)$ (29/02/2016) e quando apresentava condições de colheita dos grãos (09/05/2016), com umidade dos grãos próxima de $13 \%$, sendo a área útil da parcela experimental definida por dois metros de comprimento $\left(2 \times 0,7=1,4 \mathrm{~m}^{2}\right)$ em quatro locais das distâncias em relação ao renque, previamente definidas. Para avaliação das produções de forragem no ponto de ensilagem e de grãos, efetuou-se o corte das parcelas a $20 \mathrm{~cm}$ de altura do solo e as produções de biomassa 
(milho e capim) foram pesadas separadamente, sendo neste momento avaliadas as alturas de inserção da espiga e da planta de milho. As amostras de forragens foram encaminhadas para laboratório onde foram conduzidas para estufas com ventilação forçada por 72 horas a $65^{\circ} \mathrm{C}$, posteriormente determinando-se os teores de matéria seca do milho e do capim. Estimou-se a produtividade de silagem total pela soma das forragens de milho e de capim em cada parcela experimental, quando o milho apresentava cerca de 30 a 35\% de matéria seca. Para a determinação da produtividade de grãos, realizou-se a colheita das espigas de cada parcela e avaliação do número de fileiras por espiga e número de grãos por fileira em cinco espigas por parcela, e, após a debulha, determinou-se a produtividade de grãos, corrigida para $13 \%$ de umidade.

Os dados dos cinco tratamentos (distâncias dos renques de $1 ; 2,4 ; 3,8 ; 5,2 \mathrm{~m}$ e a pleno sol) foram submetidos à análise de variância, considerando-se um delineamento de blocos casualizados (DBC), com quatro repetições, e as médias foram comparadas pele teste de Tukey ao nível de 5\% de significância $(\mathrm{p}<0,05)$. Os dados das distâncias entre as linhas de milho e os renques de eucalipto foram submetidos à análise de regressão, e os modelos de regressão foram escolhidos com base na significância da regressão e da falta de ajustamento testada pelo teste F, na significância dos coeficientes de regressão utilizando-se o teste $\mathrm{t}$ de Student, e no coeficiente de determinação $\left(\mathrm{R}^{2}\right)$. Os dados das variáveis dependentes foram submetidos à análise de correlação de Pearson. Para as análises estatísticas foram adotados níveis de significância de 1 e 5\% de probabilidade. Os procedimentos estatísticos foram realizados utilizando o procedimento GLM do pacote computacional SAS (SAS Institute, 2000).

\section{Resultados e Discussão}

A variação da intensidade do sol incidindo sobre as culturas entre os renques de eucalipto é inconstante em função da distância do renque, e influencia a produtividade de milho, que é reduzida onde há menor irradiação (Figura 2 e 3). Nesta situação, a cultura distanciada a $1 \mathrm{~m}$ do renque recebeu em média $20 \%$ da radiação fotossinteticamente ativa (RFA) na fase inicial e vegetativa, promovendo a redução no desenvolvimento e potencial produtivo, já que apresentou as menores alturas de planta e inserção de espiga, redução no número de grãos por fileira e produtividade de forragem e de grãos (Tabela 2). A porcentagem de RFA incidente no terceiro período de avaliação (06/04/2016) foi maior na distância de um metro do renque e menor nas outras distâncias, se comparado aos outros períodos avaliados (Figura 2), possivelmente em função da estação do ano (outono) enquanto as outras foram realizadas no verão, havendo diferença entre a declinação solar das datas avaliadas, possibilitando maior entrada de luz solar nas distâncias mais próximas das árvores. Outro fato que possivelmente alterou RFA pode ser a menor influência das árvores que se desenvolveram durante o verão, com temperatura e umidade favorável, reduzindo o sombreamento intenso sobre as linhas de cultivo próximas do renque (Figura 1).

O capim apresentou maior plasticidade em relação à competição proporcionada pelo renque de eucaliptos, porém percebe-se uma tendência que se correlaciona com o desenvolvimento do milho que provavelmente exerce uma competição mais intensiva sobre o capim, limitando o seu desenvolvimento inicial, apesar de a produtividade de forragem em pleno sol ter sido superior, principalmente no período de 


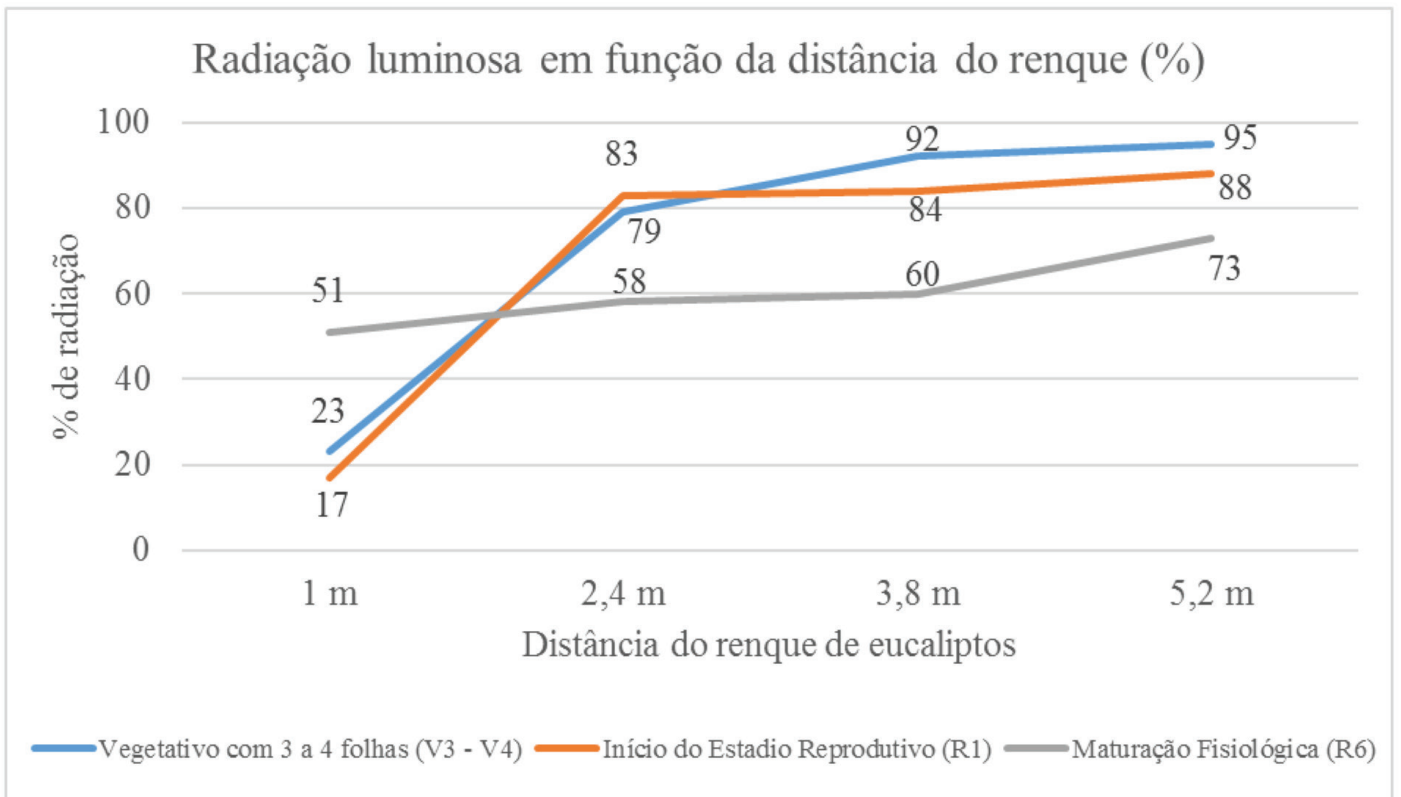

Figura 2 - Porcentagem de radiação fotossinteticamente ativa incidente sobre as diferentes distâncias do renque de eucalipto, em três diferentes datas de avaliação (16/12/2015, 01/02/2016 e 06/04/2016) que correspondem aos estádios vegetativos V3 - V4, R1 e R6, respectivamente, em Sete Lagoas-MG, 2015/16.

colheita dos grãos, correspondente a 167 dias após a semeadura (DAS) (Tabela 2). Segundo Paciullo et al. (2007), o sombreamento natural de árvores em sistema silvipastoril altera a intensidade e a qualidade da radiação que incide no sub-bosque, alterando a morfogêneses das plantas e reduzindo o perfilhamento de gramíneas.

Ressalta-se que para a área total do sistema de ILPF em espaçamento de $15 \times 2$ entre plantas de eucalipto, deve-se desconsiderar cerca de 13,3\% da área para produção de grãos e forragem, em razão do espaçamento de um metro de cada lado do renque de eucalipto, que é respeitado para não danificar as árvores com os implementos e reduzir os efeitos de competição. Sendo assim, enquanto a média de produção de silagem total apresentada na faixa (área útil) entre os renques de eucaliptos foi de 14.783 quilos de matéria seca por hectare, devemos considerar uma produtividade na área total de $12.816 \mathrm{~kg} \mathrm{ha}^{-1}(-13,3 \%)$, que corresponde a uma redução de $24,7 \%$ em relação ao alcançado no pleno sol. A média de produtividade de grãos apresentada foi de $8.656 \mathrm{~kg} \mathrm{ha}^{-1}$ mas com a redução de $13,3 \%$ da área útil, essa média passa para $7.504 \mathrm{~kg} \mathrm{ha}^{-1}$, que corresponde a uma redução de $30 \%$ da produtividade do pleno sol $(10.746 \mathrm{~kg}$ $\mathrm{ha}^{-1}$ ). Segundo Gontijo Neto et al. (2014), o cultivo de milho em consórcio com capim entre renques de eucaliptos é fortemente afetado a partir do terceiro ano de implantação do sistema ILPF, com redução da produtividade de forragem e grãos de milho, indicando que a viabilidade técnica e econômica é reduzida para cultivo de milho em sistema de ILPF no 


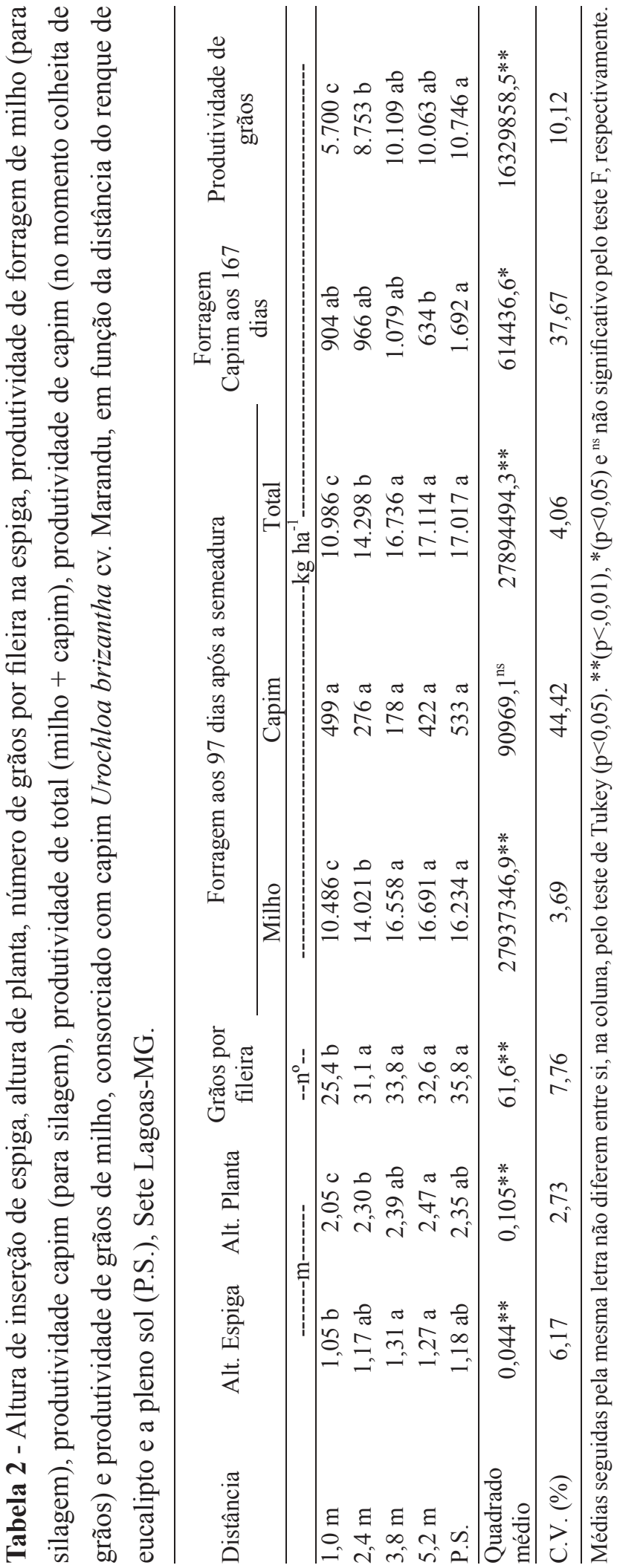

espaçamento de $15 \times 2$, possibilitando a exploração agrícola com o mínimo de interferência proporcionado pelo consórcio com árvores somente até o segundo ano do sistema.

O capim remanescente torna-se importante para a sustentabilidade do sistema. Além dos benefícios ambientais, o capim é uma fonte de alimento para a pecuária em sistema de pastejo após a colheita dos grãos de milho. Nas condições deste trabalho, o capim apresentou uma queda média de produção de $47 \%$ no momento da colheita dos grãos, em comparação com o pleno sol. Mas é importante ressaltar que sistemas ILPF têm a finalidade de melhorar a produção, a qualidade e a sustentabilidade das pastagens, além de beneficiar o desempenho animal com maior conforto térmico em função da atenuação das temperaturas promovidas pelo abrigo contra o vento, chuva e sol (Pires et al., 2010). Então, ao implantar o sistema ILPF, o produtor deve estar ciente que a produtividade da forragem e do milho é reduzida, principalmente a partir do terceiro ano de implantação do sistema (Gontijo Neto et al., 2014). Mas o sistema se beneficia com o componente arbóreo, que diversifica a renda da propriedade e futuramente pode ser utilizado como fonte de madeira, lenhas, postes e mourões, para uso interno e comercial.

Os modelos de regressão, apresentados na Figura 3, ilustram a influência do componente arbóreo, em função da distância, sobre os aspectos fitotécnico da cultura do milho entre os renques de eucalipto. Todos os fatores apresentaram redução no índice de avaliação nas fileiras mais próximas das árvores.

Esse padrão de resposta está fortemente ligado à disponibilidade de luz nas diferentes distâncias em relação ao renque de eucalipto (Figura 2), onde nas linhas mais distantes do renque tiveram menor influência da sombra e apresentaram melhor desen- 


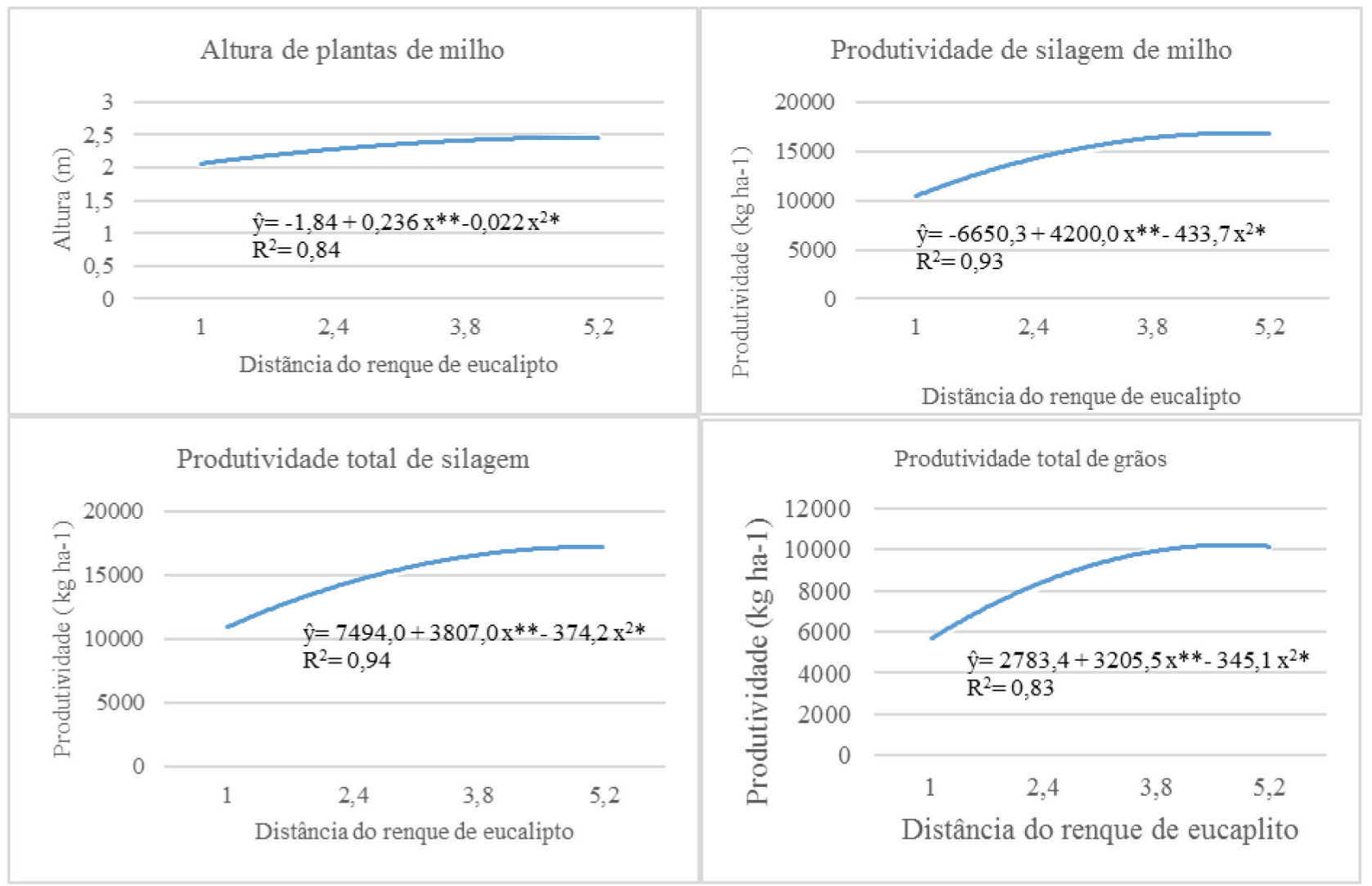

Figura 3 - Altura de planta de milho, produtividade de forragem de milho, produtividade total de forragem e produtividade de grãos de milho em função da distância do renque de eucalipto em sistema ILPF, em Sete Lagoas-MG, 2015/16.

volvimento. Perin et al. (2011) avaliaram o efeito do sombreamento na produtividade de milho em sistemas agrossilvipastoris, na região Amazônica do Brasil, e concluíram que a redução de luz nas proximidades da linha das árvores afetou negativamente a produtividade do milho. Mendes et al. (2013) também observaram a influência negativa no desenvolvimento do milho sob a copa de árvores em sistema agrossilvipastoril, na região de Sobral, no Ceará. Paciullo et al. (2007) observaram redução de produtividade de biomassa seca de capim braquiária decumbens sob sombreamento natural em sistema silvipastoril, na região da Zona da Mata Mineira. Deve-se ressaltar que além da redução de radiação nas proximidades dos renques de eucalipto existem também competição mais intensa sobre água e nutrientes no solo.

A produtividade de forragem (aos 167 dias após a semeadura) e de grão aumentou de maneira quadrática à medida que se distanciava do renque de eucalipto. A maior distância do renque apresentou um acréscimo de $35,8 \%$ da produtividade de forragem e de 43,3\% de grãos em relação à linha de semeadura mais próxima ao renque. A redução da produtividade nas linhas próxima ao renque está relacionada com o 
menor número de grãos na espiga, provavelmente por causa da menor incidência de radiação solar que influencia a produção. Conforme Didonet et al. (2002), a temperatura e a radiação incidente sobre a planta de milho são determinantes para a produtividade do milho até a fase de espigamento, pois reduzem a formação de grãos na ponta da espiga, diminuindo a relação de grãos por planta. Por isso, plantas com maior influência da copa das árvores apresentaram menor altura, produtividade de biomassa e produtividade de grãos.

Segundo Sangoi et al. (2002), a qualidade e a quantidade de luz solar que incide sobre a planta de milho intervêm na altura de planta e de inserção da espiga principal, provando a forte influência do sombreamento do eucalipto sobre o milho cultivado em sistema ILPF no terceiro ano de implantação. Campos et al. (2010), avaliando cultivares de milho na safrinha nas regiões sudoeste e norte de Goiás, onde a precipitação varia entre 1.500 e $1.800 \mathrm{~mm}$ por ano, também observaram que as condições locais de umidade, temperatura e radiação solar interferem sobre a altura de planta e de inserção de espiga. Portanto, essa alteração de tamanho de plantas de milho é influenciada pela qualidade de luminosidade e competição por água e nutrientes, promovendo alteração na produtividade de biomassa de forragem e grãos de milho.

A produtividade de capim, em função da distância do renque, não se ajustou em modelos de regressão, ficando com produtividade média, aos 97 dias após a semeadura e no momento da colheita dos grãos (167 DAS), de 343,7 e 895,7 $\mathrm{kg} \mathrm{ha}^{-1}$ de MS, respectivamente.

A radiação fotossinteticamente ativa (RFA) apresentou correlação positiva com produtividade de forragem de milho (PFMI), produtividade de forragem total (PFTOT), produtividade de grãos (PGR), número de grãos por fileira (NGFIL) e altura de planta (ALT.P). Mesmo que sem significância, podemos observar a tendência de redução do capim em função do melhor desenvolvimento do milho causado pela maior pressão de competição do milho sobre a forrageira. Para a produtividade de grãos e forragem nesse sistema, fica evidente a importância do bom desenvolvimento do milho para a boa produtividade.

Portanto, a produtividade de grãos e forragem de milho apresentou comportamento direto em função das distâncias da linha de semeadura dos renques, sendo reduzida de acordo com o aumento do nível de interceptação luminosa das árvores no sistema ILPF sobre os componentes produtivos do milho.

Conforme os resultados apresentados, a produtividade de forragem de milho e capim (forragem total ensilada + forragem de capim no ponto de grãos) na área de ILPF foi reduzida, em média 27,3\%, e em relação à produção de grãos a redução foi em torno de 30,2\% (Tabela 3), considerando a diminuição de $13,3 \%$ da área útil de produção. Se se considerar somente a área útil de produção do sistema (sem descontar 13,3\% de área a menos), houve uma redução de $16,2 \%$ da produção de forragem (forragem total ensilada + forragem de capim no ponto de grão) e de $19,4 \%$ da produção de grãos. É importante lembrar que o manejo das culturas traz benefícios para o ambiente, como a melhoria das qualidades químicas, físicas e biológicas do solo e o controle de plantas invasoras, tornando mais produtiva a pastagem que sobrevém.

Os custos fixos com semeadura, tratos culturais e colheita se mantêm em sistema de ILPF, se comparando ao cultivo em pleno sol, reduzindo a viabilidade econômica da produção de grãos e forragem, mas é importante salientar que no sistema ainda existe o componente arbóreo que agrega valor e benefícios ambientais e que não foi contabilizado neste estudo. 
Tabela 3 - Coeficientes de correlação de Pearson entre nível de radiação (RAD), produtividade de forragem de milho aos 97 dias após a semeadura (PFMI), produtividade de forragem de capim aos 97 dias após a semeadura (PFCP), produtividade de forragem total aos 97 dias após a semeadura (PFTOT), produtividade de grãos de milho (PGR), produtividade de capim no ponto de grãos 167 dias após a semeadura (PCCG), número de fileiras na espiga de milho (NFIL) e número de grãos por fileira na espiga de milho (NGFIL), altura de espiga (ALT.E) e altura de planta (ALT.P).

\begin{tabular}{lcccccccccc}
\hline & RAD. & PFMI & PFCP & PFTOT & PGR & PCCG & NFIL & NGFIL & ALT.E & ALT.P \\
\hline RAD. & 1,00 & $0,96^{*}$ & $-0,61$ & $0,96^{*}$ & $0,99 * *$ & $-0,18$ & 0,90 & $0,98^{*}$ & 0,92 & $0,98^{*}$ \\
PFMI & & 1,00 & $-0,60$ & $0,99 * *$ & $0,99 *$ & $-0,16$ & 0,77 & $0,99 * *$ & $0,99 *$ & $0,99^{*}$ \\
PFCP & & & 1,00 & $-0,57$ & $-0,57$ & $-0,67$ & $-0,32$ & $-0,56$ & $-0,59$ & $-0,51$ \\
PFTOT & & & 1,00 & $0,99 *$ & $-0,20$ & 0,78 & $0,99 * *$ & $0,99 * *$ & $0,99 *$ \\
PGR & & & & 1,00 & $-0,23$ & 0,86 & $0,99 * *$ & $0,96 *$ & $0,99 * *$ \\
PCCG & & & & & 1,00 & $-0,45$ & $-0,23$ & $-0,15$ & $-0,29$ \\
NFIL & & & & & & 1,00 & 0,84 & 0,69 & 0,87 \\
NGFIL & & & & & & & 1,00 & $0,97 *$ & $0,99 * *$ \\
ALT.E & & & & & & & & & 1,00 & $0,96 *$ \\
ALT.P & & & & & & & & & & 1,00 \\
\hline
\end{tabular}

** $(\mathrm{p}<0,01) \mathrm{e} *(\mathrm{p}<0,05)$, pelo teste Pearson, respectivamente.

\section{Conclusões}

As produtividades de grãos (milho) e forragem (milho mais capim) entre os renques de eucalipto foram semelhantes às produtividades a pleno sol a partir de 3,8 m de distância entre as linhas de milho e os renques de eucalipto.

A produtividade de grãos e de forragens foi diretamente influenciada pela redução da distância entre as linhas de semeadura e os renques de eucalipto com três anos de implantação em espaçamento de $15 \times 2$.

O componente arbóreo no sistema de Integração Lavoura-Pecuária-Floresta altera o ambiente no sub-bosque, reduzindo a incidência de radiação fotossinteticamente ativa entre os renques, diminuindo diretamente as produtividades de forragem e grãos de milho em cultivo consorciado com $U$. brizantha.

\section{Agradecimento}

Ao CNPq, pela concessão da bolsa de doutorado do primeiro e sexto autores, à rede ILPF e a Fundação Agrisus.

\section{Referências}

ANDRADE, R. G.; TEIXEIRA, A. H. de C.; LEIVAS, J. F.; SILVA, G. B. S. da; NOGUEIRA, S. F.; VICTORIA, D. de C.; VICENTE, L. E.; BOLFE, E. L. Indicativo de pastagens plantadas em processo de degradação no bioma Cerrado. In: SIMPÓSIO BRASILEIRO DE SENSORIAMENTO REMOTO, 17., 2015, João Pessoa. Anais... São José dos Campos: INPE, 2015. p. 1585-1592.

BALBINO, L. C.; CORDEIRO, L. A. M.; PORFIRIODA-SILVA, V.; MORAES, A. de; MARTINEZ, G. B.; ALVARENGA, R. C.; KICHEL, A. N.; FONTANELI, R. S.; SANTOS, H. P. dos; FRANCHINI, J. C.; GALERANI, 
P. R. Evolução tecnológica e arranjos produtivos de sistemas de integração lavoura-pecuária-floresta no Brasil. Pesquisa Agropecuária Brasileira, Brasília, DF, v. 46, n. 10, p. i-xii, out. 2011. Prefácio.

DOI: $10.1590 / \mathrm{S} 0100-204 X 2011001000001$.

CAMPOS, M. C. C.; SILVA, V. A.; CAVAlCANTE, I. H. L.; BECKMANN, M. Z. Produtividade e características agronômicas de cultivares de milho safrinha sob plantio direto no Estado de Goiás. Revista Acadêmica: Ciências Agrárias e Ambientais, Curitiba, v. 8, n. 1, p. 77-84, 2010. DOI: 10.7213/cienciaanimal.v8i1.10544.

DIDONET, A. D.; RODRIGUES, O.; MARIO, J. L.; IDE, F. Efeito da radiação solar e temperatura na definição do número de grãos em milho. Pesquisa Agropecuária Brasileira, Brasília, DF, v. 37, n. 7, p. 933-938, jul. 2002. DOI: 10.1590/S0100-204X2002000700006.

FANCELLI, A. L.; DOURADO NETO, D. Ecofisiologia e fenologia. In: FANCELLI, A. L.; DOURADO NETO, D. Produção de milho. Guaíba: Agropecuária, 2000. p. 21-54.

GONTIJO NETO, M. M.; VIANA, M. C. M.; ALVARENGA, R. C.; SANTOS, E. A. dos; SIMÃO, E. de P.; CAMPANHA, M. M. Sistema de integração lavoura-pecuária-floresta em Minas Gerais. Boletim de Indústria Animal, Nova Odessa, v. 71, n. 2, p. 183-191, 2014. DOI: 10.17523/bia.v71n2p183.

MENDES, M. M. de S.; LACERDA, C. F. de; CAVAlCANTE, A. C. R.; FERNANDES, F. E. P.; OLIVEIRA, T. S. de. Desenvolvimento do milho sob influência de árvores de pau-branco em sistema agrossilvipastoril. Pesquisa Agropecuária Brasileira, Brasília, DF, v. 48, n. 10, p. 1342-1350, out. 2013.
DOI: 10.1590/S0100-204X2013001000005.

PACIULlO, D. S. C.; CARVALHO, C. A. B.; AROEIRA, L. J. M.; MORENZ, M. F.; LOPES, F. C. F.; ROSSIELLO, R. O. P. Morfofisiologia e valor nutritivo do capimbraquiária sob sombreamento natural e a sol pleno. Pesquisa Agropecuária Brasileira, Brasília, DF, v. 42, n. 4, p. 573-579, 2007.

DOI: 10.1590/S0100-204X2007000400016.

PERIN, R.; SOUZA, J. N.; MORAIS, R. R. de; TONATO, F.; ROCHA, R. N. C. da; FONTES, J. R. A. Efeito do sombreamento na produtividade de milho em sistemas agrossilvipastoris. In: CONGRESSO BRASILEIRO DE SISTEMAS AGROFLORESTAIS, 8., 2011, Belém, PA. Anais... Belém: SBSAF: Embrapa Amazônia Oriental, 2011. 1 CD-ROM.

PIRES, M. F. A.; PACIULO, D. S. C.; PIRES, J. A. Conforto animal no Sistema Integração Lavoura-PecuáriaFloresta. Informe Agropecuário, Belo Horizonte, v. 31, n. 257, p. 81-89, 2010.

SANGOI, L.; GRACIETTI, M. A.; RAMPAZZO, C.; BIANCHET, P. Response of Brazilian maize hybrids from different eras to changes in plant density. Field Crops Research, Amsterdam, v. 79, n. 1, p. 39-51, 2002. DOI: 10.1016/S0378-4290(02)00124-7.

SAS INSTITUTE. SAS/Stat user's guide: version 9.2. Cary, 2000.

ZHU, X.-G.; LONG, S. P.; ORT, D. R. Improving photosynthetic efficiency for greater yield. Annual Review of Plant Biology, Palo Alto, v. 61, p. 235-261, 2010.

DOI: 10.1146/annurev-arplant-042809-112206. 